\title{
Erratum to: Experimental and Theoretical Optimization of Radio Frequency Hollow Cathode Discharge
}

\author{
Xin-Xian Jiang ${ }^{1,2} \cdot$ Wei-Ping $\mathrm{Li}^{3} \cdot$ Shao-Wei $\mathrm{Xu}^{4}$ • \\ ${\text { Feng } \mathrm{He}^{5} \cdot \text { Qiang Chen }}^{6}$
}

Published online: 24 February 2017

(C) Springer Science+Business Media New York 2017

\section{Erratum to: Plasma Chem Plasma Process DOI 10.1007/s11090-016-9770-x}

The original version of the article contained an error in the article title. The title is corrected as "Experimental and Theoretical Optimization of Radio Frequency Hollow Cathode Discharge" and has been updated with this erratum.

The online version of the original article can be found under doi:10.1007/s11090-016-9770-x.

Xin-Xian Jiang

jxx052310382@126.com

1 Department of Mechanical Engineering, School of Physics, Tsinghua University, Beijing 100084, China

2 North Microelectronics Co. Ltd, Beijing 100176, China

3 The Quartermaster Research Institute of General Logistics Department, Chinese People Liberation Army, Beijing 100010, China

4 China Academy of Space Technology, Beijing Institute of Space Mechanics and Electricity, Beijing 100094, China

5 School of Physics, Beijing Institute of Technology, Beijing 100081, China

6 Laboratory of Plasma Physics and Materials, Beijing Institute of Graphic Communication, Beijing 102600, China 